Actelion, Bayer, BMS, Boehringer, Roche, Sanofi, Margarida Alves Employee of: Employee of Boehringer Ingelheim, Nicole Graf Grant/research support from: Received consulting fees or other remuneration from Astellas and Biotronik, Paolo Airò: None declared, Lidia P. Ananyeva: None declared, László Czirják: None declared, Serena Guiducci: None declared, Eric Hachulla Consultant for: Received consulting fees or other remuneration from Actelion, GSK, Pfizer, and Bayer, Mengtao Li: None declared, Carina Mihai Consultant for: Received consulting fees or other remuneration from Actelion, Geneva, Roche, and Rofarm, Consultant for: F. Hoffmann-La Roche, Actelion, Geneva Romfarm, Gabriela Riemekasten Consultant for: Chugai, F. Hoffmann-La Roche, Speakers bureau: Chugai, F. Hoffmann-La Roche, Petros Sfikakis: None declared, Gabriele Valentini Grant/research support from: Received research funding and other remuneration from AbbVie, BMS, Lilly, Pfizer, and Sanofi, Consultant for: Received consulting fees and other remuneration from AbbVie, BMS, Lilly, Pfizer, and Sanofi, Otylia Kowal-Bielecka Consultant for: Received consulting fees or other remuneration from Bayer, Boehringer Ingelheim, Inventiva, Medac, Novartis, and Roche, Oliver Distler Grant/research support from: Prof. Distler received research funding from Actelion, Bayer, Boehringer Ingelheim and Mitsubishi Tanabe to investigate potential treatments of scleroderma and its complications, Consultant for: Prof. Distler has/had consultancy relationship within the last 3 years with Actelion, AnaMar, Bayer, Boehringer Ingelheim, ChemomAb, espeRare foundation, Genentech/Roche, GSK, Inventiva, Italfarmaco, iQvia, Lilly, medac, Medlmmune, Mitsubishi Tanabe Pharma, Pharmacyclics, Novartis, Pfizer, Sanofi, Serodapharm and UCB in the area of potential treatments of scleroderma and its complications. In addition, he had/has consultancy relationship within the last 3 years with A. Menarini, Amgen, Abbvie, GSK, Mepha, MSD, Pfizer and UCB in the field of arthritides and related disorders

DOI: 10.1136/annrheumdis-2019-eular.2586

\section{OP0240 ASSESSMENT OF PULSE WAVE VELOCITY IN SYSTEMIC SCLEROSIS: POTENTIAL BENEFICIAL EFFECTS OF BOSENTAN ON FOREARM ARTERIAL STIFFNESS? AN EXPLORATORY STUDY}

Anniek van Roon ${ }^{1}$, Amaal Eman Abdulle ${ }^{1}$, Saskia van de Zande ${ }^{1}$, Arie Van Roon ${ }^{1}$ Dan Zhang ${ }^{2}$, Reinhard Bos ${ }^{2}$, Hendrika Bootsma ${ }^{3}$, Andries Smit ${ }^{1}$, Douwe J Mulder ${ }^{1}$ University of Groningen, University Medical Center Groningen, Internal Medicine, division Vascular Medicine, Groningen, Netherlands; ${ }^{2}$ Medical Center Leeuwarden, Rheumatology, Leeuwarden, Netherlands; ${ }^{3}$ University of Groningen, University Medical Center Groningen, Rheumatology and Clinical Immunology, Groningen, Netherlands

Background: Systemic sclerosis (SSc)-related vasculopathy is generally thought to occur on a microvascular level. However, some observations also suggest involvement of arterial vessels. Macrovascular involvement (e.g., aorta or upper extremity) can be non-invasively assessed by measuring pulse wave velocity (PWV). Although, several studies have assessed aortic and upper extremity PWV in SSc, studies have not reached a consensus regarding this matter. Furthermore, we hypothesized that the endothelin antagonist bosentan may improve arterial stiffness by its direct endothelial and potential anti-fibrotic effects.

Objectives: The aim of this exploratory study was two-fold. First, we aimed to compare arterial stiffness in patients with SSc and age and sex-matched healthy controls $(\mathrm{HC})$. Secondly, we will investigate the effect of bosentan on both shortterm (three month) and long-term (one year) PWV.

Methods: Baseline differences between $\mathrm{HC}$ and SSc patients were studied in a case-control design. The follow-up of SSc patients was a randomized, prospective, 2-arm parallel group, open-label, (usual care with bosentan versus usual care only), blinded endpoint, intervention study. PWV (Sphygmocor) in meters/ second, was measured to assess arterial stiffness in the aorta (carotid-femoral PWV), upper arm (carotid-brachial PWV), and forearm (brachial-radial PWV), adjusted for mean arterial pressure.

Results: Baseline characteristics are shown in table 1. No significant differences were observed in PWV (at all sites) between $\mathrm{HC}$ and SSc patients. No effect of bosentan on aortic, and upper arm PWV was found. The change in forearm PWV was different between the groups, with a decrease (e.g. lowering arterial stiffness) in the bosentan group (figure 1)

Table 1. Baseline characteristics

\begin{tabular}{lcccc} 
Table 1. Baseline characteristics & $\begin{array}{c}\text { Healthy } \\
\text { controls } \\
(\mathbf{n}=19)\end{array}$ & $\begin{array}{c}\text { Systemic } \\
\text { sclerosis } \\
\text { patients } \\
(\mathbf{n}=19)\end{array}$ & $\begin{array}{c}\text { Bosentan } \\
\text { group } \\
(\mathbf{n}=9)\end{array}$ & $\begin{array}{c}\text { Usual } \\
\text { care } \\
\text { group } \\
(\mathbf{n}=7)\end{array}$ \\
\hline Female, $\mathrm{n}(\%)$ & $13(69)$ & $13(69)$ & $5(56)$ & $6(86)$ \\
Age in years, median (IQR) & $53(47-$ & $50(44-54)$ & $52(49-$ & $44(43-$ \\
& $63)$ & & $66)$ & $54)$ \\
Pack years, median (IQR) & $0(0-7.5)^{\star}$ & $2.5(0-30.6)^{\star}$ & $17.3(0.7-$ & $0.8(0-$ \\
& & & $34.1)$ & $2.75)$
\end{tabular}

Body mass index in $\mathrm{kg} / \mathrm{m}^{2}$, median (IQR)

Systolic blood pressure in $\mathrm{mm} \mathrm{Hg}$, median (IQR)

Diastolic blood pressure in $\mathrm{mm} \mathrm{Hg}$, median (IQR)

Raynaud's phenomenon duration in years, median (IQR)

Systemic sclerosis disease duration since first non-Raynaud symptom in years, median (IQR)

*difference between groups with a $p<0.05$

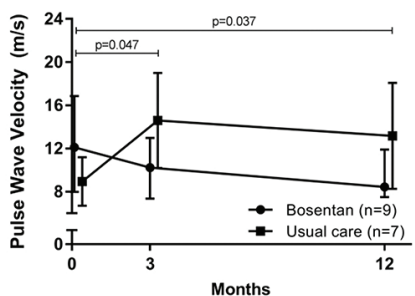

Figure 1. The median (IQR) of the brachial-radial pulse wave velocity over time of the bosentan and usual care group

Conclusion: This small study shows that aortic, upper arm, and forearm arterial stiffness does not appear to be increased in patients with SSc, as compared to age- and sex-matched healthy controls. To the best of our knowledge, this is the first study to investigate the concept of potential effects of an endothelin receptor antagonist on macrovascular involvement in SSc. Although the results demon strate no effects on aorta and upper arm arterial stiffness, they may indicate a beneficial effect on the stiffness of the smaller arteries of the forearm. Future studies are needed to further investigate the potential effect of bosentan on these smaller arteries.

Acknowledgement: Actelion for co-funding the study

Disclosure of Interests: Anniek van Roon: None declared, Amaal Eman Abdulle : None declared, Saskia van de Zande: None declared, Arie Van Roon: None declared, Dan Zhang: None declared, Reinhard Bos Grant/research support from: SUN Pharma, Hendrika Bootsma Grant/research support from: Unrestricted grants from Bristol-Myers Squibb and Roche, Consultant for: Roche, Bristol-Myers Squibb, Novartis, Medimmune, Union Chimique Belge, Speakers bureau: Bristol-Myers Squibb, Novartis, Andries Smit Shareholder of: Has been co-founder, and is still shareholder of Diagnoptics Technologies, the company which developed the AGE reader., Douwe J Mulder Grant/research support from: My University has received research grants for my research from: Boehringer Ingelheim and Actelion, Speakers bureau: My University has received speakers fee from: Sanofi

DOI: 10.1136/annrheumdis-2019-eular.6756

\section{OP0241 \\ SAFETY AND EFFICACY OF LENABASUM IN AN OPEN-LABEL EXTENSION OF A PHASE 2 STUDY OF LENABASUM IN REFRACTORY SKIN-PREDOMINANT DERMATOMYOSITIS (DM) SUBJECTS}

Victoria Werth $^{1,2}$, David Pearson ${ }^{1,2}$, Joyce Owaka ${ }^{1,2}$, Rui Feng $^{2}$, Josef Simon Concha ${ }^{1,2}$, Basil Patel ${ }^{1,2}$, Emily Hejazi ${ }^{1,2}$, Caitlin Cornwall ${ }^{3}$, Scott Constantine ${ }^{3}$, Nancy Dgetluck ${ }^{3}$, Barbara White ${ }^{3}$. ${ }^{1}$ Philadelphia Veteran Affairs Medical Center, Philadelphia, United States of America; ${ }^{2}$ University of Pennsylvania, Philadelphia, United States of America; ${ }^{3}$ Corbus Pharmaceuticals, Inc., Norwood, United States of America

Background: Lenabasum is a synthetic, non-immunosuppressive, selective cannabinoid receptor type 2 agonist that activates resolution of innate immune responses. Lenabasum had acceptable safety and tolerability and improved efficacy outcomes in the initial 16-week double-blinded, randomized, placebo-controlled Part A of Phase 2 trial JBT101-DM-001 (NCT02466243) in dermatomyositis (DM) subjects with refractory, skin-predominant involvement. Objectives: To provide long-term safety and efficacy data in DM subjects in this study.

Methods: Subjects who completed Part A were eligible to receive oral lenabasum $20 \mathrm{mg}$ BID in an open-label extension (OLE) that assessed safety and efficacy at 4 weeks, then every 8 weeks.

Results: 20/22 (90.9\%) eligible subjects received open-label lenabasum, following a mean interval of 31 weeks from end of Part $A$, during which when they received only standard-of care, to start of OLE during which lenabasum $20 \mathrm{mg}$ BID was added. $17 / 20(85.0 \%)$ subjects were on stable baseline 